\title{
IDOSOS PRIVADOS DE LIBERDADE: EXPECTATIVAS SOBRE A VIDA APÓS CUMPRIMENTO DA PENA
}

\author{
Alessandra Minervina dos Santos Lopes ${ }^{1}$, Claudia Tedde', Maria Fernanda Pereira Gomes², \\ Elza de Fátima Ribeiro Higa ${ }^{1}$, Maria José Sanches Marin ${ }^{1}$ e Carlos Alberto Lazarini ${ }^{1}$ \\ ${ }^{1}$ Faculdade de Medicina de Marília - SP, Brasil. alessandra_minervina@hotmail.com; claudia_tedde@yahoo.com.br; \\ marnadia@terra.com.br; carlos.lazarini@gmail.com \\ 2Universidade Paulista, Assis - SP, Brasil.mferpg@usp.br
}

\begin{abstract}
Resumo. Introdução: O idoso, desde o momento em que é preso, se confronta com mudanças significativas na sua vida social e afetiva, envolvendo as crenças e valores que tem a respeito do outro e de si próprio. Objetivos: compreender as expectativas do idoso privado de liberdade sobre a vida após o cumprimento da pena. Métodos: Pesquisa qualitativa, fundamentada na Teoria das Representações Sociais. Participaram 42 idosos privados de liberdade de quatro penitenciárias da região oeste do estado de São Paulo, Brasil. Os dados foram obtidos por meio de entrevistas semiestruturadas e organizados pela técnica do Discurso do Sujeito Coletivo. Resultados: Da análise dos dados obtidos na pergunta "Como você imagina sua vida quando estiver em liberdade?" emergiram quatro ideias centrais: serventia a Deus, recomeço no seio familiar, ressocialização e desesperança. Considerações: As representações sociais enfatizaram a importância do relacionamento e apoio familiar, da crença e do retorno a vida social após sua liberdade, a dignidade mesmo com as perdas provocadas pela privação da liberdade.
\end{abstract}

Palavras-chave: Idoso; Prisioneiros; Representações Sociais.

\section{ELDERLY DEPRIVED OF LIBERTY: LIFE EXPECTANCY AFTER SERVING THE SENTENCE}

Abstract. Introduction: The elderly, from the moment of their imprisonment, face significant changes in their moral life, involving the beliefs and values they have about the other and about themselves. Objectives: to understand the expectations of the elderly person deprived of freedom for their life after serving their sentence. Methods: Qualitative study, based on the Theory of Social Representations. 42 elderly people deprived of liberty from four penitentiaries in the west region of the São Paulo state participated. The data were obtained through semi-structured interviews and organized using the Collective Subject Discourse technique. Results: From the question "Speak how do you imagine your life when you are free?" four central ideas emerged: serving God, starting over in the family, hopelessness and resocialization. Considerations: The reports of the deprived elderly allowed to understand the social representations about the importance of belief, family relationship and support and the return to social life after their freedom, with dignity, even with the losses that life itself was responsible for bringing.

Keywords: Elderly; Prisoners; Social Representations.

\section{INTRODUÇÃO}

O envelhecimento é uma realidade, devido ao aumento da expectativa de vida do brasileiro nos últimos anos, fato esse também presente no sistema prisional. Nesse contexto, os idosos privados de liberdade estão sujeitos as dificuldades relacionadas a alimentação, saúde, acomodação, que de certa forma intensificam as características fisiológicas da velhice (Shapiro, 2001). 
Em 2008, os idosos privados de liberdade correspondiam a 0,73\% da população carcerária brasileira, ou seja, 3.328 idosos para um total de 451.219 privados de liberdade. Em 2016 essa porcentagem alcançou 1\% de toda população carcerária do país (Brasil, 2017). Segundo dados do Levantamento Nacional de Informações Penitenciarias (INFOPEN), em dezembro de 2019 existiam 773.151 mil pessoas privadas de liberdade no Brasil, sendo o terceiro país com maior número de pessoas encarceradas, ficando atrás somente dos Estados Unidos e China (Brasil, 2020).

Estudo sobre o significado do envelhecimento para idosos privados de liberdade, em um estado da região nordeste do Brasil, demonstrou sentimentos de melancolia, angústia e constantes perdas, causadas pela impossibilidade de qualquer tipo de desenvolvimento sociocultural e afetivo. A dificuldade para exercer atividade laboral, a diminuição do convívio familiar e os conflitos intergeracionais corroboram a perda da qualidade de vida dos idosos no cárcere (Oliveira, Costa, \& Medeiros, 2013).

A Resolução da Secretaria de Administração Penitenciária (SAP) - 144 (2010) que instituiu o Regimento Interno Padrão das Unidades Prisionais do Estado de São Paulo em seu Art. 93 aponta: "As visitas têm a finalidade de preservar e estreitar as relações do preso com a sociedade, a família, a companheira e os parentes, sob vigilância e com limitações, ressocializando-o e reintegrando-o de forma espontânea ao âmbito familiar e comunitário, quando do cumprimento da sua pena, bem como as visitas tem caráter terapêutico objetivando desenvolver e aprimorar o senso de comunhão social na esfera das unidades prisionais".

Ao considerar a importância da família para o encarcerado, é preciso atentar também para o fato de que esse encarceramento acarreta grandes danos ao seu círculo familiar, sendo necessário investir em soluções penais mais adequadas, como programas de trabalho e educação, entre outras, que promovam uma real reinserção desse indivíduo à sociedade, em consonância com seu contexto social e familiar (Brasil, 2017).

No ano de 2016, a SAP através da Resolução SAP - 138 (2016) regulamenta a Jornada de Cidadania e Empregabilidade, um evento realizado anualmente nas Unidades Prisionais do Estado de São Paulo, por meio da Coordenadoria de Reintegração Social e Cidadania (CRSC) com o objetivo de oferecer aos reeducandos um conjunto de serviços essenciais para auxiliá-los na retomada da vida em liberdade, trazendo para dentro do sistema penitenciário um mutirão de ações para fornecer importantes ferramentas no processo de 
reintegração social. São exemplo de ações realizadas nestas jornadas: retirada de documentos (Registro Geral - RG, Cadastro de Pessoa Física - CPF, Certidões Diversas, Carteiras de Trabalho, Título de Eleitor e outros), atendimento jurídico, atendimentos e exames de saúde, cortes de cabelo e procedimentos estéticos, palestras e oficinas de parceiros, entre outras atividades (Governo do Estado de São Paulo, 2020a).

Uma penitenciária de um estado da região nordeste do Brasil desenvolve ações que levam aos idosos atividades recreativas e artísticas, proporcionando também a interação social, tendo em vista a dificuldade de aproximação que enfrentam no dia-a-dia por motivos diversos, ainda não atendendo a todas as necessidades dessas pessoas. O Projeto Envelhecer no Cárcere é o único momento em que as pessoas idosas tem acesso a atividades que tem por objetivo restabelecer a dignidade dos apenados. Pensando na ressocialização, este projeto deveria ser oferecido pelo Estado em todo sistema penitenciário Brasileiro (Ascesunita, 2016).

Como a população carcerária brasileira não para de crescer, a situação do Sistema Prisional do país é um problema que só vem se agravando, pois apresenta superlotação e não oferece aos seus apenados as condições mínimas e necessárias para punição adequada e ressocialização (Araújo \& Mendes, 2016).

Frente ao exposto, essa pesquisa emerge da seguinte inquietação: quais as expectativas sobre a vida que o idoso tem após sua liberdade do sistema prisional? Dessa forma, apresentou como objetivo compreender as expectativas sobre a vida do idoso privado de liberdade após o cumprimento da pena.

\section{METODOLOGIA}

\subsection{Tipo de pesquisa}

Trata-se de uma pesquisa com abordagem qualitativa. Os dados foram discutidos sob os fundamentos da Teoria das Representações Sociais (TRS). O conceito de representação social compreende a concepção que um sujeito, um grupo ou uma sociedade têm sobre determinado tema ou assunto, estando presente tanto nas relações sociais como no conjunto de opiniões e comportamentos dos indivíduos, refletindo em sua conduta e valores. Moscovici apresenta a seguinte definição: "Em poucas palavras, a representação social é 
uma modalidade de conhecimento particular que tem por função a elaboração de comportamentos e a comunicação entre indivíduos" (Moscovici \& Cabral, 1978, p. 26).

A Teoria das Representações Sociais, teoria do senso comum ou teoria do saber ingênuo, contribui com a investigação proposta, uma vez que busca compreender como o conhecimento produzido pela ciência é transformado no tecido social - nos universos consensuais; ou ainda como aquilo que não é familiar é tornado familiar, como o distante é tornado próximo para a vida prática cotidiana. Além disso, a referida teoria contribui com as pesquisas que intencionam investigar as representações sociais formadas nas imbricações do social com o individual ou do coletivo com o psicológico de grupos específicos (Jodelet, 2001). Para esta autora, a representação é um modo de saber material que vincula o sujeito ao objeto, possui determinados atributos peculiares que são: é sempre a representação de alguém (sujeito) ou algo (objeto); nelas estão contidas as propriedades do sujeito ou do objeto; a relação entre o sujeito e o objeto está simbolizada e interpretada na representação social, imputa-Ihe significações que são derivadas de um movimento de exteriorização levantado pelo sujeito, este movimento pode nos levar a processos intelectuais ou mentais, pode ser analisado como epistemológico, psicológicos, seus modos de saber e mensurar este saber utilitário e experiente, sendo que este último item acena para o fato de como ele é produzido e que implica em ações sobre o universo e o outro no contexto social; e é exibida como um molde do objeto nos diferentes tipos de linguagem ou comportamentos.

Os universos consensuais ou do senso comum são atmosferas onde se encontram o familiar, aquilo que é conhecido. Para se alcançar o familiar, atravessamos o processo de ancoragem que é a dessensibilização e o reconhecimento do objeto e, de objetivação que conecta a imagem da não-familiaridade ao que é verdadeiro, transformando-se em real (Moscovici, 2017).

Segundo Duveen (2001), tanto Moscovici quanto Piaget compartilham da postura epistemológica - o mundo tal como o conhecemos é construído por nós por meio de nossas operações psicosociológicas e para compreensão das representações sociais é preciso entender os processos por meio dos quais são produzidas e transformadas.

\subsection{Local do estudo}

Para a coleta dos dados optou-se por uma amostra intencional, sendo selecionados 42 idosos que recebem visita. Nessa abordagem foram selecionadas quatro unidades prisionais 
da região oeste do Estado de São Paulo que juntas abrigam um total de 7.489 encarcerados, dos quais 101 são idosos (60 anos ou mais). Os critérios de exclusão ocorreram nas seguintes condições: trânsito (fora da unidade prisional), cumprindo de sansão disciplinar, estar hospitalizado ou apresentar déficit cognitivo que impossibilite de responder a entrevista.

Entre as penitenciárias que foram aplicadas as entrevistas, uma é de grande importância por ser responsável pelo encarceramento feminino, o qual tem apresentado alto índice nos últimos 10 anos no Brasil.

\subsection{Coleta de dados}

Realizou-se por meio de um roteiro de entrevista semiestruturada. Este tipo de entrevista oferece um amplo campo de ação ao pesquisador e foi composta da seguinte pergunta aberta: Como você imagina a sua vida quando estiver em liberdade?

No momento que antecedeu a realização das entrevistas, pela própria pesquisadora, que passou por revista de rotina realizada pelo Scanner corporal de cada unidade prisional, antes de adentrar no local estipulado para realização de cada entrevista. Foram explicados os objetivos do projeto e fornecida a garantia do anonimato dos depoimentos de cada idoso. Os que concordaram em participar da pesquisa foram levados para uma sala estipulada pela unidade prisional. Após a leitura minuciosa do Termo de Consentimento Livre e Esclarecido (TCLE), explicando os detalhes, o motivo, objetivos da pesquisa e riscos, as entrevistas foram áudio-gravada em aparelho de MP3 para posterior transcrição e análise das informações obtidas. Após esta etapa, as gravações foram inutilizadas. A coleta de dados foi realizada no interior do cárcere no período de 10 de março à 20 de junho de 2019.

\subsection{Organização dos dados}

O processamento dos dados foi realizado por meio da técnica do Discurso do Sujeito Coletivo (DSC) que preconiza o tratamento das mensagens verbais que podem ser faladas ou escritas e são advindas de depoimentos dos participantes, constituído por um conjunto de procedimentos de tabulação e organização de dados discursivos e discutidos à luz da Teoria das Representações Sociais, enquanto fenômeno representativo dos participantes (Lefèvre, 2017). 
Esse mesmo autor traz que a técnica do DSC permite resgatar as Representações Sociais provenientes de dados de pesquisas empíricas, onde as opiniões ou expressões de cada indivíduo são agrupadas em categorias semânticas gerais, desde que apresentem sentidos semelhantes. Com o sujeito coletivo, os discursos não se anulam ou se reduzem a uma categoria comum unificadora, já que o que se busca fazer é precisamente o inverso, ou seja: reconstruir, com pedaços de discursos individuais, como em um quebra-cabeça, tantos discursos-síntese quantos se julgue necessário para expressar uma dada "figura", um dado pensar ou uma representação social sobre um fenômeno (Lefèvre, 2017).

As seguintes figuras metodológicas constituem esta técnica: Expressão-chave (ECH); Idea central (IC); Ancoragem (AC); e Discursos de Sujeito Coletivo (DSC). As ECH são segmentos contínuos ou descontínuos de mensagens emitidas, que revelam o principal do conteúdo das respostas obtidas, uma espécie de "prova discursivo-empírica" da "verdade" representadas nas ideias centrais. A IC é elaborada a partir da síntese do conteúdo das $\mathrm{ECH}$ e representa a marca e identidade do discurso, concebida pelo pesquisador e coerente com os achados. A AC é evidenciada quando o participante da pesquisa professa em sua mensagem a referência a alguma teoria ou lei que ampare a sua ideia. O DSC é construído com base na união das $\mathrm{ECH}$ e $\mathrm{AC}$, referentes às $\mathrm{IC}$, em um discurso síntese associado ao conteúdo das opiniões individuais com sentidos semelhantes, possibilitando construir um discurso relativo a uma coletividade na voz de apenas um representante, sempre redigido na primeira pessoa do singular (Lefèvre, 2017).

Neste sentido, o DSC representa um recurso metodológico, que nesta pesquisa foi destinado a tornar mais claras e expressivas as representações sociais dos idosos privados de liberdade, no qual cada participante se reconheça como autor e emissor de discursos comuns compartilhados entre seus membros.

\subsection{Aspectos éticos}

Esta pesquisa só foi iniciada após aprovação pelo Comitê de Ética e Pesquisa com seres Humanos de uma faculdade pública de um município do interior do Estado de São Paulo, sob número CAAE 94672918.7.0000.5413, conforme determina a Resolução 510 (2016) do Conselho Nacional de Saúde. Após aprovação por esse comitê, o projeto foi encaminhado para o Comitê de Ética em pesquisa do sistema prisional do Estado de São Paulo e aprovado sob número CAAE 94672918.7.3002.5563. Para apresentação dos resultados, os 
idosos foram codificados por meio da letra I, seguida de uma sequencia numérica crescente $11 \ldots . \mid 42$.

\section{RESULTADOS}

Para análise, foram utilizadas 42 entrevistas realizadas com os idosos privados de liberdade, que em algum momento recebiam visitas, sendo $76,2 \%$ do sexo masculino. Dos dados obtidos por meio da pergunta "Como você imagina a sua vida quando estiver em liberdade?" emergiram quatro IC.

A primeira IC "Serventia a Deus" permitiu a construção do seguinte DSC: "Não me revolto, converso muito com Deus e faço minhas orações. Deus foi maravilhoso comigo, tenho saúde. Aqui dentro procurei uma igreja, me converti na evangélica, minha esposa sempre quis que fosse para esta igreja. Quero casar com ela e vou batizar, descer nas aguas e vou continuar servindo. É o que minha família toda pretende. Agradeço a Deus todos os dias em minhas orações, ele teve misericórdia de mim. Meu objetivo é criar uma igreja, é uma bênção de Deus." (I1, I2, 14, I5, I8, I9, I10, I12, I13, I14, I15, I19, I20, I22, I23, I24, I25, I26, I28, I29, I30, I31, I32, I33, I34, I35, I36, I37, I38, I39, I40, I41 e 142)

A segunda IC "Recomeço no seio familiar" traz o seguinte DSC: "Recomeçar e sonhar os planos familiares, voltar e cuidar da minha família já que tenho o apoio deles, estar junto e não mais pensar no que passou. O apoio da família existe, mas a cobrança também. Espero encontra-los com saúde e me esperando de braços abertos. Vou procurar fazer o melhor para eles, dar carinho para minha esposa, meus filhos e netos. Tenho certeza que eles vão estar lá fora me esperando." (I1, I4, I9, I10, I12, I13, I14, I15, I23, I26, I30, I32, I35, I36, I39, 141 e 142)

"Ressocialização", terceira IC, permitiu construir o DSC: "O recomeço não é nada fácil porque sou um ex detendo. Isso é um obstáculo muito difícil, estou reeducando minha consciência aqui dentro para quando sair estar apto a conviver em sociedade, respeitar a todos, evitar certos tipos de coisas que a gente não pode mais fazer. Peço a Deus para voltar tudo ao normal. Fiz um curso aqui dentro do sistema. Se puder quero fazer outros cursos, pretendo quando sair abrir uma padaria. Vou procurar trabalhar, estudar, não sei ler direito, tenho dificuldade em assinar até meu nome. Vou continuar com minha vida e 
aproveitar esse tempo perdido, que joguei fora." (I1, I2, I4, I5, I10, I11, I13, I14, I15, I16, I18, $119,127,128,129,135$ e 142)

A quarta IC "Desesperança" permitiu a construção do seguinte DSC: "Ajudei muita gente e hoje eu não recebo uma carta. Hoje só lamento pela minha família, não ter amado mais, não ter lutado mais, tem tanta coisa que eu podia ter feito e não fiz. Complicado até para arrumar serviço, pois agora é difícil, já estou velho e acho que quando sair daqui minha mãe não estará mais viva." (I1, I3, I16, I23 e I34)

\section{DISCUSSÃO}

A primeira IC remete a representação social da religião e serventia a Deus enquanto forma de apoio pessoal, como demonstrado no fragmento do DSC "Agradeço a Deus todos os dias em minhas orações, ele teve misericórdia de mim".

A Lei de Execução Penal (LEP) (Lei n. 7.210, 1984) assegura ao preso assistência religiosa, com liberdade de culto e permite a posse de livros de instrução religiosa. Neste sentido, a Lei n. 9.982 (2000) também assegura o acesso dos religiosos e religiosas de todos os credos aos estabelecimentos prisionais. No caso das prisões, a religião oferece apoio na vivência de situações adversas, interfere positivamente no ambiente e colabora no ajustamento dos presos (Ribeiro \& Minayo, 2014).

Estudo realizado com 368 mulheres privadas de liberdade em São Paulo associou menor frequência de transtornos mentais à maior religiosidade pessoal. A religiosidade parece atuar como fator de integridade emocional tanto para homens quanto para mulheres, subsidiando auxílio no enfrentamento das mazelas características da condição do cárcere (Ranuzi, 2018).

A segunda IC remete a representação social sobre o recomeço no seio familiar, após o cumprimento da pena. A família acaba sendo o eixo de referência pelo qual seus participantes elaboram e determinam suas relações sociais, passando a se organizarem em torno da realização de projetos comuns, construídos de acordo com a realidade em que os seus componentes estão inseridos. Neste sentido, possuem uma diversidade de estrutura que enfatiza o lugar de valor que "a família" e os modelos familiares ocupam numa dada sociedade (Santos, 2017). Este fato está implícito no seguinte fragmento do DSC 
"Recomeçar e sonhar os planos familiares, voltar e cuidar da minha família já que tenho o apoio deles, estar junto e não mais pensar no que passou".

A literatura aponta que a reinserção do indivíduo no ciclo familiar provoca mudanças inevitáveis devido ao abalo emocional que ambos sofreram durante o cárcere, sendo iniciado o processo de readaptação. Esse processo consiste no fortalecimento dos laços afetivos, de modo que tanto a família quanto o ex-presidiário consigam superar todas as dificuldades impostas durante o período de cumprimento de pena (Cabral \& Medeiros, 2014), fato esse presente no seguinte fragmento do DSC "O apoio da família existe, mas a cobrança também." Essa fase é de suma importância para que o indivíduo não se sinta desamparado e retorne ao sistema prisional (Cabral e Medeiros, 2014).

O DSC da terceira IC remete a representação social do recomeço e as possibilidades de reintegrar-se na vida social após as mudanças que ocorreram no passado. Quando a data de libertação se aproxima, e se poderia pensar que o maior desafio já foi ultrapassado, estes idosos têm agora que enfrentar o processo de reinserção em sociedade como exreclusos (Cordeiro, 2018).

A vida pós encarceramento para indivíduos com mais de sessenta e cinco anos distingue-se da reintegração social de qualquer outro prisioneiro por inúmeros motivos. Um dos principais consiste no fato do idoso ter consciência de que o tempo restante de vida em liberdade é escasso, o que gera consequências na forma como observa e lida com a sua reintegração em sociedade (Cordeiro, 2018).

A SAP conta com a Coordenadoria de Reintegração Social e Cidadania responsável por promover a ressocialização de apenados e egressos do sistema penitenciário paulista por meio de ações técnicas, gerenciais e políticas que efetivem a reintegração social e cidadania de pessoas em situação de vulnerabilidade frente ao sistema penal. Além dessa coordenação, o Grupo de Ações de Reintegração Social (GARS) é responsável pela realização de iniciativas para ressocialização com ênfase nas Unidades Prisionais do Estado de São Paulo. Os programas e projetos são promovidos de acordo com a realidade das penitenciárias, visando contemplar as características de cada público (Governo do Estado de São Paulo, 2020b).

O "Programa de Atenção ao Egresso e Família" é uma política pública que tem por finalidade dar assistência direta ao egresso do sistema penitenciário e também aos seus 
familiares. Esse programa é operacionalizado pelas Centrais de Atenção ao Egresso e Família (CAEF), localizadas em diversos municípios do Estado de São Paulo, que promovem ações voltadas à educação, saúde, geração de trabalho e renda, apoio psicossocial e jurídico (Governo do Estado de São Paulo, 2020b).

A quarta IC remete a representação social do desânimo dos idosos em situação de privação de liberdade. A desesperança, enquanto sentimento subjetivo, tem sua representação social mediante eventos externos que acometem os indivíduos e de forma interna os causam uma sensação de obscuridade ou ausência de percepções positivas futuras, principalmente tratando-se de idosos privados de liberdade que estão a mercê de um fator que lhes foge ao controle: o passar do tempo (Fernandes \& Andrade, 2016).

Pode-se dizer que a desesperança está relacionada ao sentimento de incapacidade ou de frustrações. No caso do idoso privado de liberdade, tais sentimentos se revelam a partir de uma visão negativa em um contexto auto derrotista, impulsionados pela ausência de figuras sociais que tragam perspectivas positivas de futuro ou de atividades que conduzam tais idosos para sentimentos de realização pessoal e capacidade própria de autossatisfação (Oliveira, Santos, Cruvinel, \& Néri, 2006).

Essa sensação de desesperança está presente no fragmento do DSC “Hoje só lamento pela minha família, não ter amado mais, não ter lutado mais, tem tanta coisa que eu podia ter feito e não fiz".

A dificuldade do relacionamento interpessoal intergeracional na prisão devido à falta de identidade dos idosos com os demais leva uma tendência ao isolamento. Ao mesmo tempo, uma das consequências de um longo período de privação de liberdade é a fragilização das redes familiares. O passar dos anos reduz a frequência de visitas, o contato com o mundo exterior e o apoio familiar, fundamentais não só emocionalmente, mas também materialmente (insumos levados para dentro da prisão) (Santos \& Nogueira, 2015). Nesse sentido, o DSC "Ajudei muita gente e hoje eu não recebo uma carta." corrobora esta afirmação.

\section{CONCLUSÕES}

Os relatos dos idosos privados de liberdade permitiram compreender as representações sociais sobre a importância da crença, do relacionamento e apoio familiar e do retorno a 
vida social após sua liberdade, com dignidade mesmo com as perdas que a própria vida se encarregou de trazer.

Considerando que esta pesquisa foi fundamentada nos pressupostos da Teoria das Representações Sociais, vale destacar a amplitude alcançada por meio das figuras metodológicas que permitiram a objetivação e ancoragem das mensagens presentes nos discursos dos participantes, que são permeadas por percepções e significados individuais dos sujeitos que as compõem.

Por fim, acredita-se ser importante a realização de futuras pesquisas que evidenciem como a população estudada possa ser melhor assistida ao final do período de encarceramento e após o cumprimento da pena. Com isso, pode ser possível subsidiar a criação de políticas públicas eficientes que devem estar integradas por meio do Plano Nacional de Política Criminal e Penitenciaria, que levem em conta o princípio da responsabilidade e que garantam a inclusão social dos idosos privados de liberdade.

\section{REFERÊNCIAS}

Araújo, H., \& Mendes, R. (2016). A situação do idoso encarcerado no Brasil. Anais do Simpósio de TCC e Seminário de Iniciação Científica, Brasília, DF, Brasil. Recuperado de http://nippromove.hospedagemdesites.ws/anais_simposio/arquivos_up/documentos/artigos/183b4eb9f77df 720dd26abf19458d2a6.pdf

Ascesunita. (2016). Projeto Envelhecer no cárcere realiza atividade na Penitenciária Juiz Plácido de Souza. Recuperado de https://asces-unita.edu.br/2016/03/14/projeto-envelhecer-no-carcere-realiza-atividade-napenitenciaria-juiz-placido-de-souza/

Brasil. (2017). Levantamento nacional de informações penitenciárias: atualização - junho de 2016. Brasília, DF: Ministério da Justiça e da Segurança Pública, Departamento Penitenciário Nacional.

Brasil. (2020). Levantamento nacional de informações penitenciárias atualização - junho de 2019. Brasília, DF: Ministério da Justiça e da Segurança Pública, Departamento Penitenciário Nacional.

Cabral, T. Y., \& Medeiros, B. A. (2015). A família do preso: efeitos da punição sobre a unidade familiar. Revista Transgressões, 2(1), 50-71. Recuperado de https://periodicos.ufrn.br/transgressoes/article/view/6652/5148

Cordeiro, A. (2018). Depois da Prisão - A Reintegração Social de Idosos (Dissertação de Mestrado). Universidade do Minho, Braga, Rortugal. Recuperado de http://repositorium.sdum.uminho.pt/handle/1822/55915

Duveen, G. (2001). Genesis and sctructure: Piaget and Moscovici. In F. Buschini \& N. Kalampalikis (Eds.), Penser la vie, le social, la nature. Mélanges en l'honneur de Serge Moscovici (pp. 163-173). Paris: La Maison de Sciences de l'Homme.

Fernandes, J. S. G., \& Andrade, M. S. (2016). Representações sociais de idosos sobre velhice. Arquivos $\begin{array}{llll}\text { Brasileiros de } \quad \text { Psicologia, } & \text { 68(2), }\end{array}$ http://pepsic.bvsalud.org/pdf/arbp/v68n2/v68n2a05.pdf

Governo do Estado de São Paulo. (2020a). A Coordenadoria. Recuperado de http://www.sap.sp.gov.br/crsc.html 
Governo do Estado de São Paulo. (2020b). Ações de Reintegração. Recuperado de http://www.sap.sp.gov.br/crsc/acoes-reintegracao.html

Jodelet, D. (2001). Representações sociais: Um domínio em expansão. In D. Jodelet (Ed.), As representações sociais (pp. 17- 44). Rio de Janeiro, RJ: EdUERJ.

Lefèvre, F. (2017). Discurso do sujeito coletivo: nossos modos de pensar, nosso eu coletivo. São Paulo, SP: Andreoli.

Lei n. 7.210, de 11 de julho de 1984. (1984). Institui a Lei da Execução Penal. Diário Oficial da União. Brasília, DF.

Lei n. 9.982, de 14 de julho de 2000. (2000). Dispõe sobre a prestação de assistência religiosa nas entidades hospitalares públicas e privadas, bem como nos estabelecimentos prisionais civis e militares. Diário Oficial da União. Brasília, DF.

Moscovici, S. (2017). Representações sociais: investigações em psicologia social. (11a ed.). Petrópolis, RJ: Vozes.

Moscovici, S., \& Cabral, T. Á. (1978). A representação social da psicanálise. Rio de Janeiro, RJ: Zahar.

Oliveira, K. L., Santos, A. A. A., Cruvinel, M., \& Néri, A. L. (2006). Relação entre ansiedade, depressão e desesperança entre grupos de idosos. Psicologia em Estudo, 11(2), 351-359. doi: 10.1590/S141373722006000200014.

Oliveira, L. V., Costa, G. M. C., \& Medeiros, K. K. A. S. (2013). Envelhecimento: significado para idosos encarcerados. Revista Brasileira de Geriatria e Gerontologia, 16(1), 139-148. doi: 10.1590/S180998232013000100014.

Ranuzi, C. (2018). Pensamento suicida, depressão e religiosidade em uma população privada de liberdade (Dissertação de mestardo). Universidade Federal do Triângulo Mineiro- UFTM, Uberaba, MG, Brasil. Recuperado de http://bdtd.uftm.edu.br/handle/tede/740?mode=full

Resolução n. 510, de 7 de abril de 2016. (2016). Sobre a Ética na Pesquisa na área de Ciências Humanas e Sociais. Diário Oficial da União. Brasília, DF.

Resolução SAP - 138, de 15 de setembro de 2016. (2016). Regulamenta, na Secretaria da Administração Penitenciária, a Jornada de Cidadania e Empregabilidade. Diário Oficial. São Paulo, SP.

Resolução SAP - 144, de 29 de junho de 2010. (2010). Regimento interno padrão das unidades prisionais do estado de São Paulo. Diário Oficial. São Paulo, SP.

Ribeiro, F. M. L., \& Minayo, M. C. S. (2014). O papel da religião na promoção da saúde, na prevenção da violência e na reabilitação de pessoas envolvidas com a criminalidade: revisão de literatura. Ciência \& Saúde Coletiva, 19(6), 1773-1789. doi: 10.1590/1413-81232014196.13112013.

Santos, C. S. L., \& Nogueira, A. Z. Q. (2015). Envelhecer em contexto prisional. Revista Brasileira de Geriatria e Gerontologia, 18(1), 39-48. doi: 10.1590/1809-9823.2015.14040.

Santos, M. N. C. (2017). Análise das propostas e normativas brasileiras relacionadas à assistência à família das pessoas privadas de liberdade no sistema prisional brasileiro nos anos de 2010 a 2016 (Trabalho de conclusão de curso). Universidade de Brasília, Brasília, DF, Brasil. Recuperado de https://bdm.unb.br/handle/10483/17495

Shapiro, B. (2001). America's Aging Prison Population: Issues \& Alternatives. In Offerder Programs. Social and Behavioral Rehabilitation in Prisons, Jails and the Community (Cap. 5, vol. 2, pp. 17-21). 